Application of porous silicon microcavity to enhance photoluminescence of $\mathrm{ZnO} / \mathrm{PS}$ nanocomposites in UV light emission

$$
\text { Hongyan Zhang }{ }^{\text {a* }} \text {, Zhenhong Jia }{ }^{\mathrm{b}}
$$

${ }^{a}$ School of Physical Science and Technology, Xinjiang University, Urumqi 830046, PR

\title{
China
}

${ }^{\mathrm{b}}$ College of Information Science and Engineering, Xinjiang University, Urumqi 830046,

\section{PR China}

E-mail: zhanghongyanxj@ 163.com 
Abstract: This paper presents $\mathrm{ZnO}$ nanostructures deposited on porous silicon (PS) and porous silicon microcavity (PSM) substrates by sol-gel method. The effects of annealing temperature and mass ration of zinc acetate to PVA on microstructure, and optical properties of $\mathrm{ZnO} / \mathrm{PS}$ and $\mathrm{ZnO} / \mathrm{PSM}$ nanocomposites were systematically investigated by field-emission scanning electron microscopy (FESEM), X-ray diffraction (XRD) and photoluminescence (PL) spectroscopy. The XRD analysis confirmed that the $\mathrm{ZnO} / \mathrm{PS}$ nanocomposite preferred strongly to (002) phase orientation. The PL spectra showed that there was a sharp and highly intense UV emission peak located at about $400 \mathrm{~nm}$ when annealing temperature was $800{ }^{\circ} \mathrm{C}$ for 30 min and the mass ratio of zinc acetate to PVA was 4:1. The detail cross-section FESEM images of $\mathrm{ZnO} / \mathrm{PSM}$ showed that $\mathrm{ZnO}$ nanoparticles uniformly penetrated into all PS layers and adhered to them very well. Furthermore, ZnO/PSM nanocomposites showed relatively stronger UV emissions at around $400 \mathrm{~nm}$ compared to the PL spectra of $\mathrm{ZnO} / \mathrm{PS}$ nanocomposites, that means one-dimension phonic crystal PSM can enhance the PL intensity of $\mathrm{ZnO}$. Such a method may provide an interesting way to develop a new type of UV optoelectronic devices.

Keywords: ZnO; Sol-gel; Porous silicon microcavity; Electrochemical etching; UV light enhancement 


\section{Introduction}

Zinc oxide $(\mathrm{ZnO})$ is a II -VI semiconductor with a wide gap $(3.37 \mathrm{eV})$ and a large excitation binding energy $(60 \mathrm{MeV})$ at room temperature (RT), which has attracted significant interests in the past few decades due to its unique properties and great potential for ultraviolet (UV) light emitters, optoelectronic devices, solar cells and chemical sensors [1-4]. Stable and strong luminescences of $\mathrm{ZnO}$ nanocrystals have been synthesized by means of vapor deposition (PVD), chemical bath deposition (CBD), electrochemical reaction, solvothermal methods [5-8], sol-gel method and organometallic synthesis, etc. Among those methods, sol-gel method draws increased interests because its low growth temperature, simplicity, potential for large-scale production and environmentally friendly processing. In recently years, $\mathrm{ZnO}$ nanostructures grown on Si-based substrates receive a significant attention since silicon is widely used in semiconducting devices [9-10]. However, there is a mismatch in their thermal expansion coefficients and lattice between $\mathrm{ZnO}$ and $\mathrm{Si}$ substrate, which prevents the $\mathrm{ZnO}$ layer from being directly grown or deposited on the $\mathrm{Si}$ substrate [11].

Porous silicon (PS) has sponge-like structure, large internal surface-to-volume ratio [12-13], adjustable roughness and special structure, which can reduce the mismatch between $\mathrm{ZnO}$ nanostructures and $\mathrm{Si}$ substrates. It becomes a good substrate for $\mathrm{ZnO}$ nanostructure growing without using metal catalysts [14-17]. Moreover, study shows that the intensity of UV emission is higher for PS compared to $\mathrm{Si}$, indicating that there is an improvement of the crystallinity of $\mathrm{ZnO}$ nanostructures due 
to free exciton emission [18]. In recent years, PS-based optical devices are widely used for photonic design, benefited from the easy preparation of PS by periodically altering etching time and etching current [19-25]. Among the photonic structures, porous silicon microcavity (PSM) attracts great interests of many scientists due to its interesting optical properties such as high reflectivity stop band with a sharp reflectance dip in the center of reflectance spectrum. Furthermore, the presence of the Fabry-Perot resonator modifies the optical mode density inside the structure thereby suppressing emitted wavelength outside the resonance and enhancing resonance wavelengths [26].

In this study, we fabricated and optimized the $\mathrm{ZnO} / \mathrm{PS}$ nanocomposites by sol-gel method. For the first time, PSM structure as a substrate for $\mathrm{ZnO} / \mathrm{PSM}$ nanocomposite was successfully fabricated. Such a $\mathrm{ZnO} / \mathrm{PSM}$ showed much stronger PL intensity than that of $\mathrm{ZnO} / \mathrm{PS}$ in the range of ultraviolet (UV) light. The present process provides an effective method for the production of $\mathrm{ZnO} / \mathrm{PSM}$, which may be an interesting way to develop a new UV optoelectronic device.

\section{Experiments}

\subsection{Characterizations}

All spectra were measured at room temperature. Structural analysis was carried out using X-ray diffraction (XRD, Bruker D8, Cu and Germany). Photoluminescence spectra were measured by the excitation of Xe lamp (Hitachi, F-4600, and Japan) with an excitation wavelength of $320 \mathrm{~nm}$. Reflectance spectra and absorption spectra were 
measured by UV-vis scanning spectrophotometer (Hitachi, U-4100, and Japan) with a resolution of $0.1 \mathrm{~nm}$, and the measured angle was 5 degree with respect to the substrate plain. Cross-sectional and surface images were obtained by a field-emission scanning electron microscope (Hitachi, S4800, and Japan).

\subsection{Preparations of $\mathrm{ZnO} / \mathrm{PS}$ nanocomposites}

In experiments, all p-type silicon substrates (resistivity $0.01-0.02 \Omega \bullet \mathrm{cm},<1 \quad 0 \quad 0>$ orientation) with a thickness of $420 \pm 10 \mu \mathrm{m}$ were cut into $2 \times 2 \mathrm{~cm}^{2}$ and cleaned with a solution of carbinol, alcohol and deionized water successively. PS layers were fabricated by electrochemical etching with a current density of $50 \mathrm{~mA} / \mathrm{cm}^{2}$ for $1 \mathrm{~min}$ in the mixed solution composed of $49 \%$ aqueous hydrofluoric acid (HF) and ethanol with the volume ratio of $1: 1$. The effective exposed area of Si substrate was $0.785 \mathrm{~cm}^{2}$ in teflon electrochemical etch cell with a copper immersed into the electrolyte as a counter electrode. Then the prepared fresh PS was soaked into $\mathrm{H}_{2} \mathrm{O}_{2}(30 \%)$ for $24 \mathrm{~h}$ at RT, and the substrates were cleaned with deionized water and dried in the air.

The precursor solution of $\mathrm{ZnO}$ was prepared using zinc acetate dihydrate as a precursor, deionized water as a solvent and polyvinyl alcohol (PVA) as a stabilizer. Firstly, zinc acetate was dissolved in DI water and PVA was added to the mixture (the mass ratio of zinc acetate to PVA was maintained at 3:1, 4:1 and 5:1). Secondly, after the PVA was added, the mixture was heated up to $80{ }^{\circ} \mathrm{C}$ for $2 \mathrm{~h}$ to yield a clear and homogenous solution and then the solution was aged at RT for $24 \mathrm{~h}$. Thereafter, the prepared oxidized PS was soaked into the precursor solution of $\mathrm{ZnO}$ for $24 \mathrm{~h}$ at $\mathrm{RT}$ and 
then the $\mathrm{ZnO}$ coated PS substrates were annealed at different temperature $\left(700^{\circ} \mathrm{C}, 800\right.$ ${ }^{\circ} \mathrm{C}$, and $900{ }^{\circ} \mathrm{C}$ ) for $30 \mathrm{~min}$.

\subsection{Preparations of $\mathrm{ZnO} / \mathrm{PSM}$ nanocomposites}

PSM is a one-dimensional photonic crystal constituted of a Fabry-Perot cavity in between two Bragg reflectors (DBRs). The reflectance maximum appears at Bragg wavelength $\left(\lambda_{0}\right)$ with a relation: $m \lambda_{0} / 2=n_{L} d_{L}+n_{H} d_{H}$. The multilayer PS structure was constructed by low refractive index layers $\left(\mathrm{n}_{\mathrm{L}}\right)$ and high refractive index layers $\left(\mathrm{n}_{\mathrm{H}}\right)$ with an effective optical thickness of $\lambda_{0} / 4$ for each DBR layer and $\lambda_{0}$ for the central layer. In our experiments, the periodic multilayer structures of PS films were fabricated by using a computer program (Labview) to alternately change current density for different etching time with a $5 \mathrm{~s}$ pause after each layer formation. The sequence of PSM was $\left(n_{L} n_{H}\right)^{6} n_{L c}\left(n_{H} n_{L}\right)^{6}$, where for low refractive index layer $\left(n_{L}\right)$ the current density was $50 \mathrm{~mA} / \mathrm{cm}^{2}$ for $1.1 \mathrm{~s}$, for high refractive index layer $\left(\mathrm{n}_{\mathrm{H}}\right)$ the current density was $20 \mathrm{~mA} / \mathrm{cm}^{2}$ for $1.7 \mathrm{~s}$, and microcavity layer $\left(\mathrm{n}_{\mathrm{Lc}}\right)$ was formed by employing a current density of $50 \mathrm{~mA} / \mathrm{cm}^{2}$ for $4.5 \mathrm{~s}$. Then the fresh PSM substrate was soaked into $\mathrm{H}_{2} \mathrm{O}_{2}(30 \%)$ for $24 \mathrm{~h}$ at RT, rinsed with deionized water and dried in the air. The oxidized PSM was soaked into the precursor solution of $\mathrm{ZnO}$ for $24 \mathrm{~h}$ (the mass ratio of zinc acetate to PVA were maintained at 4:1) and then the $\mathrm{ZnO}$ coated PSM substrates were annealed at $800{ }^{\circ} \mathrm{C}$ for $30 \mathrm{~min}$.

\section{Results and Discussions}

3.1 $\mathrm{ZnO} / \mathrm{PSM}$ affected by annealing temperature 


\subsubsection{SEM images}
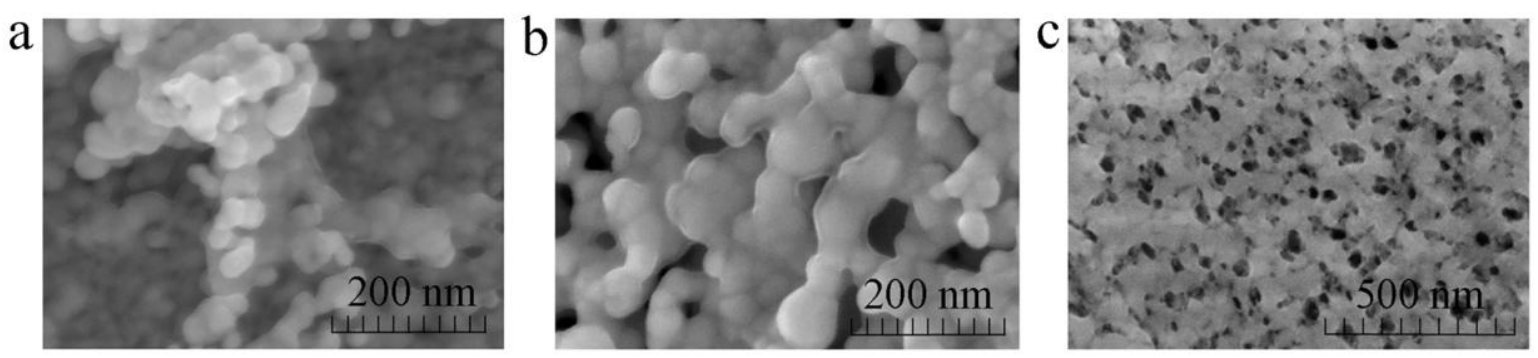

Fig. 1. Plan-view FESEM images of ZnO/PS at different annealing temperatures:

$$
\text { (a) } 700{ }^{\circ} \mathrm{C} \text {, (b) } 800{ }^{\circ} \mathrm{C} \text { and (c) } 900{ }^{\circ} \mathrm{C} \text {. }
$$

Fig.1 shows the surface morphology of nanostructured $\mathrm{ZnO}$ on oxidized PS substrates when the annealing temperature was separately set to be $700^{\circ} \mathrm{C}, 800^{\circ} \mathrm{C}$, and $900{ }^{\circ} \mathrm{C}$. We can see that all PS substrates are densely covered by interleaved $\mathrm{ZnO}$ nanoparticles. In Fig.1 (a), the shape of $\mathrm{ZnO}$ nanoparticles is quasi-spherical with a size ranging from $20 \mathrm{~nm}$ to $50 \mathrm{~nm}$ when the annealing temperature was $700{ }^{\circ} \mathrm{C}$. In Fig. 1(b), $\mathrm{ZnO}$ nanostructures show a smoother surface and a more uniform diameter compared to Fig. 1(a). In Fig. 1(c), the $\mathrm{ZnO}$ nanoparticles become large enough to form clusters when the annealing temperature was increased up to $900{ }^{\circ} \mathrm{C}$. So we can conclude that the $\mathrm{ZnO}$ nanostructures become more compact and denser with the annealing temperature increasing, and the surface morphology of $\mathrm{ZnO}$ nanostructures is significantly depended on annealing temperature.

\subsubsection{UV-visible absorption studies}




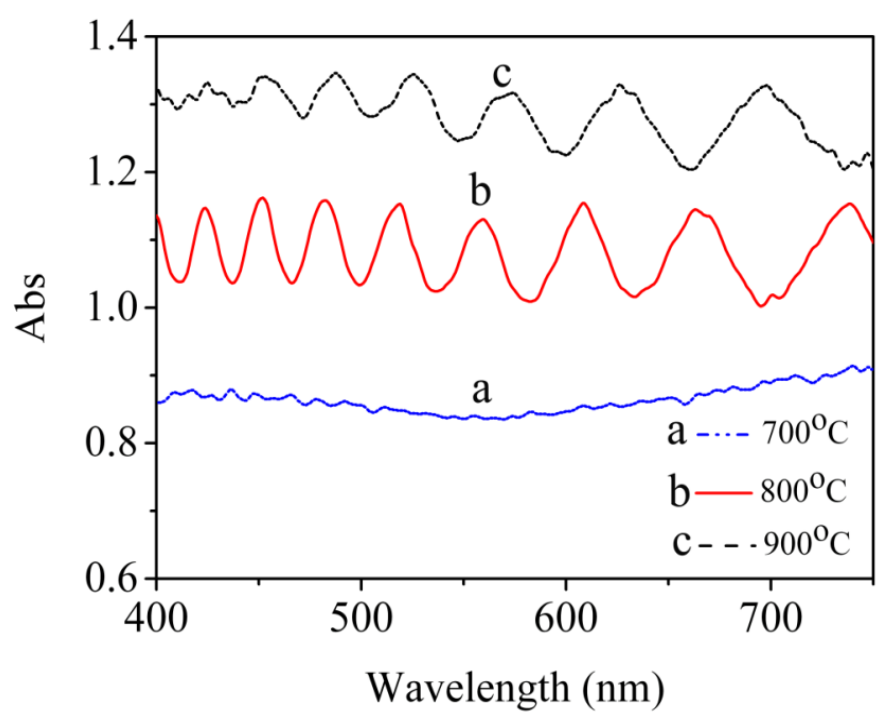

Fig. 2. UV-visible adsorption spectra of $\mathrm{ZnO/PS}$ nanocomposites at different annealing temperatures: (a) $700{ }^{\circ} \mathrm{C}$, (b) $800{ }^{\circ} \mathrm{C}$ and (c) $900{ }^{\circ} \mathrm{C}$.

In order to fabricate $\mathrm{ZnO} / \mathrm{PSM}$ nanocomposites with a high quality, it is important to study the annealing temperature-dependent optical properties of this material. Fig.2 shows the evolution of ultraviolet-visible absorption spectra with different annealing temperatures changing from $700{ }^{\circ} \mathrm{C}$ to $900{ }^{\circ} \mathrm{C}$. It can be observed that average absorptance increases with the annealing temperature, which is resulted from the size of $\mathrm{ZnO}$ nanostructures getting more compact and denser. Moreover, sharp absorption edges with a clear shift to longer wavelength and more periods of the absorptance within UV-wavelength can be observed when the annealing temperature is increased to $800^{\circ} \mathrm{C}$. This may be due to the decrease in optical scattering when the crystal sizes of $\mathrm{ZnO}$ nanoparticles are getting larger, smoother and more uniform in diameter, causing a reduction in the density of grain boundaries, which plays an important role in the scattering of photons [23]. These conclusions are consistent with 
the statistical results as shown in Fig. 1.

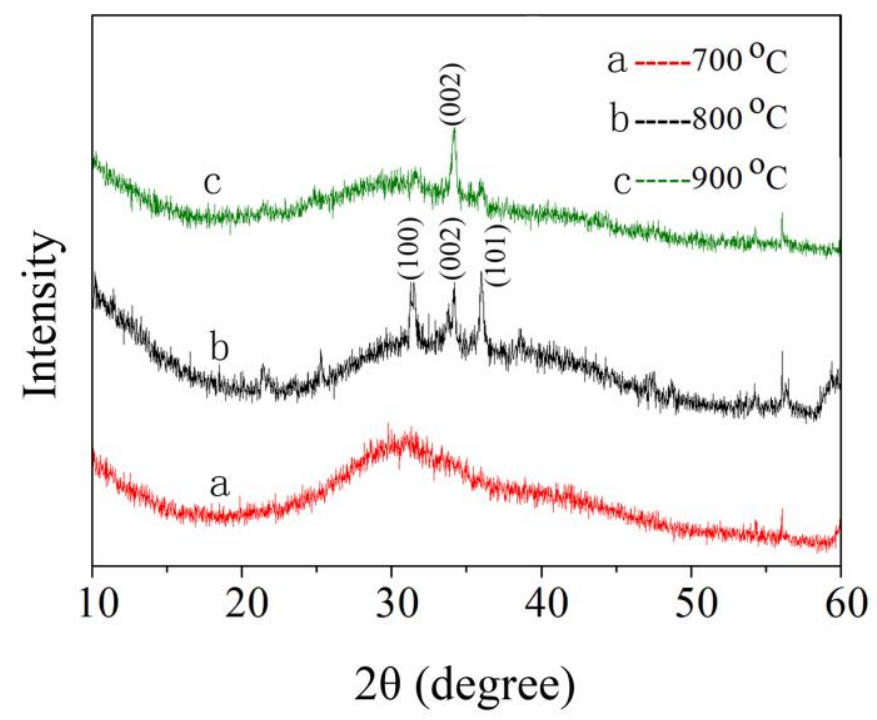

Fig.3. XRD patterns of $\mathrm{ZnO} / \mathrm{PS}$ nanocomposites at different temperatures: (a) $700{ }^{\circ} \mathrm{C}$,

$$
\text { (b) } 800{ }^{\circ} \mathrm{C} \text { and (c) } 900{ }^{\circ} \mathrm{C} \text {. }
$$

\subsubsection{XRD studies}

To study the effects of annealing temperature on crystal structure, we performed XRD measurements on the $\mathrm{ZnO} / \mathrm{PSM}$ composite. Fig.3 shows the XRD patterns of samples annealed separately at $700{ }^{\circ} \mathrm{C}, 800{ }^{\circ} \mathrm{C}$ and $900{ }^{\circ} \mathrm{C}$ with successive $30 \mathrm{~min}$. In Fig.3 (a), the dominant peak of $\mathrm{ZnO}$ is not observed in the XRD spectrum for $\mathrm{ZnO} / \mathrm{PSM}$ nanocomposites when the annealing temperature is $700{ }^{\circ} \mathrm{C}$. In Fig.3 (b), three diffraction peaks appear in spectra of $\mathrm{ZnO} / \mathrm{PS}$ nanocomposites at $2 \theta$ from $10^{\circ}$ to $60^{\circ}$ when the temperature is increased to $800{ }^{\circ} \mathrm{C}$, corresponding to the $(100),(002)$ and (101) directions of hexagonal $\mathrm{ZnO}$ wurtzite. All the X-ray diffraction peaks are well indexed as the wurtzite structure (hexagonal phase, space group P63mc) of $\mathrm{ZnO}$ 
with lattice parameters $a, b=0.325 \mathrm{~nm}$ and $c=0.521 \mathrm{~nm}$ (JCPDs. No.36-1451). The presence of (100), (002) and (101) peaks indicates that $\mathrm{ZnO}$ nanoparticles were not grown perfectly vertical to the PS substrate surface but at a random angle. From Fig.3 (c), a relatively high intensity of (002)-oriented peak (c-axis orientation) at $34.09^{\circ}$ is observed when the temperature is increased to $900{ }^{\circ} \mathrm{C}$, indicating part of $\mathrm{ZnO}$ nanostructures are grown parallel to the surface of PS substrate. The intensity of the (002) oriented peak increases with the increasing of annealing temperature, indicating that the preferred growth orientation of $\mathrm{ZnO}$ nanostructures is moving toward to the c-axis. This result can be explained in terms of the low surface free energy of the (002) plane $[17,27]$. Furthermore, the strong intensity and narrow width of $\mathrm{ZnO}$ diffraction peaks also indicate that the resulting products have good crystallinity.

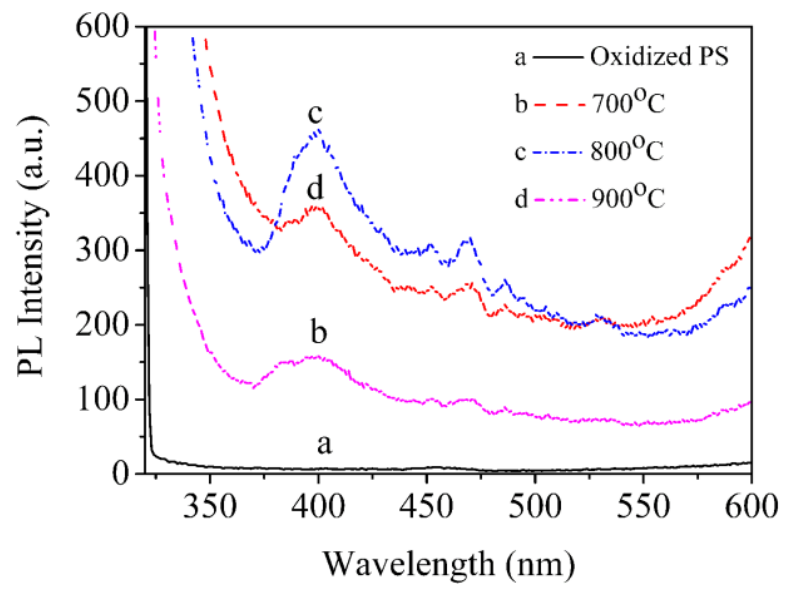

Fig.4. Room-temperature PL spectra $(\lambda \operatorname{exc}=310 \mathrm{~nm})$ of (a) oxidized PS, and $\mathrm{ZnO} / \mathrm{PS}$ nanocomposites at different annealing temperatures: (b) $700^{\circ} \mathrm{C}$, (c) $800^{\circ} \mathrm{C}$ and(d) $900^{\circ} \mathrm{C}$.

3.1.4 Photoluminescence studies 
PL emission spectrum provides valuable information for the relaxation pathways of excited states and enables to determinate structural defects within $\mathrm{ZnO}$ thin film. Fig.4 shows PL spectra of oxidized PS and the deposited ZnO/PS nanocomposites at different annealing temperatures for 30 min. From Fig.4 (a), negligible PL can be observed for oxidized PS substrate. In Fig.4 (b), (c) and (d), there are two obvious peaks in the PL spectra of $\mathrm{ZnO} / \mathrm{PS}$ nanocomposites, where the peak with stronger intensity is located at around $400 \mathrm{~nm}$ and the weaker one is located at around $470 \mathrm{~nm}$. The peak at $400 \mathrm{~nm}$ in the UV region corresponds to the band gap of free excitations or the near-band-edge emission of $\mathrm{ZnO}$ wide band gap generated by the recombination of photo-generated charge carriers [27-29]. The peak at $470 \mathrm{~nm}$ in the blue region of the visible spectrum can be associated with the internal defects such as oxygen vacancies. The weaker blue-green emission of $\mathrm{ZnO} / \mathrm{PS}$ nanocomposites might be related to the higher oxygen vacancy concentration with the annealing temperature being increased.

From Fig.4, we can see that the intensity of UV emission is strongly influenced by surface condition of $\mathrm{ZnO}$ nanostructures. When the annealing temperature is increased from $700^{\circ} \mathrm{C}$ to $800^{\circ} \mathrm{C}$, the PL peak position shifts from $398 \mathrm{~nm}$ to $396 \mathrm{~nm}$ and the PL intensity is increased (Fig.4 b and Fig. 4c). The slightly blue shift may be due to the size increase and surface shape transition to be more smooth and more uniform in diameter for $\mathrm{ZnO}$ nanoparticles. When the annealing temperature is increased up to $900^{\circ} \mathrm{C}$, the defect is declined and crystallization is improved, so a significant decrease for PL intensity is observed. 
The surface of the PS layer is composed of numerous nano-silicon crystals, and the rough surface morphology forms a wetting layer by decreasing the surface energy. Such nano-silicon crystals, distributed randomly on the entire surface, would act as nucleation sites, which enables $\mathrm{ZnO}$ nanoparticles to grow along the preferred orientation. Annealing temperature in $\mathrm{ZnO}$ growth process has an important effect on shape, size and alignment of $\mathrm{ZnO}$ nanoparticles, and hence influences optical properties of $\mathrm{ZnO} / \mathrm{PS}$ nanocomposites.

\section{2 $\mathrm{ZnO} / \mathrm{PS}$ effected by precursor solution of $\mathrm{ZnO}$}

\subsubsection{SEM images}
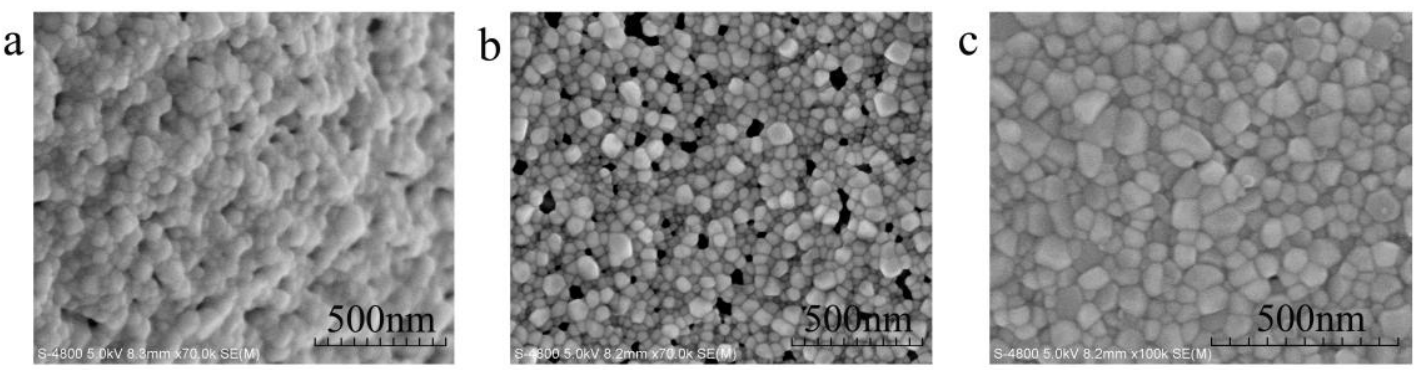

Fig. 5. Plan-view FESEM images of $\mathrm{ZnO} / \mathrm{PS}$ nanocomposites at $800{ }^{\circ} \mathrm{C}$ with different mass ratios of zinc acetate to PVA: (a) 3:1, (b) 4:1 and (c) 5:1.

Fig.5 shows the surface morphology of $\mathrm{ZnO}$ nanoparticles doped on PS substrate with a mass ratio of zinc acetate to PVA to be $3: 1,4: 1$ or $5: 1$ with the same annealing temperature of $800{ }^{\circ} \mathrm{C}$ for $30 \mathrm{~min}$. Highly-densed $\mathrm{ZnO}$ nanoparticles are uniformly distributed over entire oxidized PS substrates. In Fig. 5(a), the sizes of quasi-spherical $\mathrm{ZnO}$ nanoparticles range from $20 \mathrm{~nm}$ to $80 \mathrm{~nm}$. In Fig. 5(b), $\mathrm{ZnO}$ nanoparticles form a smooth surface with a uniform diameter ranging from $50 \mathrm{~nm}$ to $80 \mathrm{~nm}$. In Fig. 5(c), 
the size ranges from $50 \mathrm{~nm}$ to $100 \mathrm{~nm}$, where nanoparticles grow into larger grains. In conclusion, the $\mathrm{ZnO}$ nanoparticles on PS are getting larger and more irregular with the mass ratio of zinc acetate to PVA being increased from 3:1, 4:1 to 5:1.

\subsubsection{Photoluminescence studies}

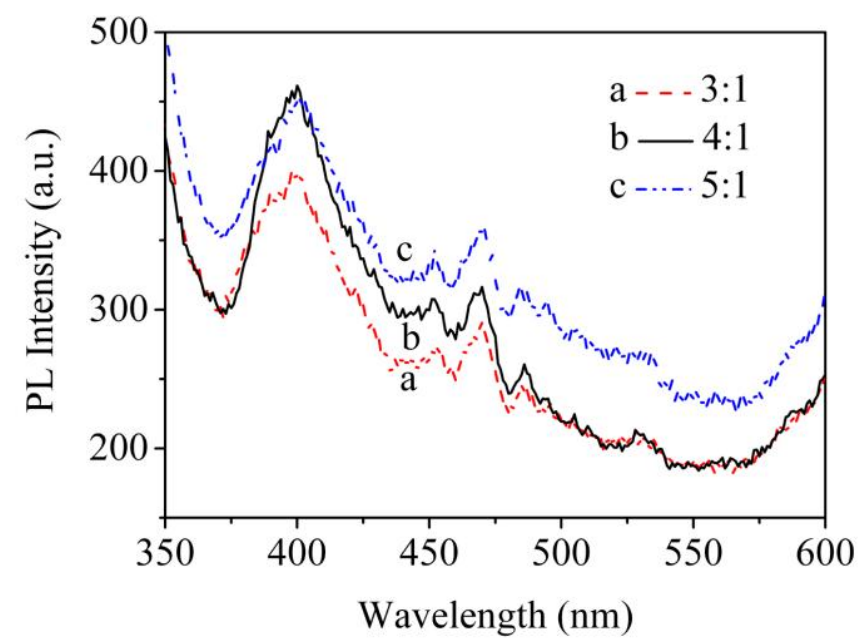

Fig. 6 Room-temperature PL spectra $(\lambda \operatorname{exc}=310 \mathrm{~nm})$ of $\mathrm{ZnO} / \mathrm{PS}$ nanocomposites with different mass ratios of zinc acetate to PVA: (a) 3:1, (b) 4:1 and (c) 5:1.

Fig. 6 presents the PL spectra of $\mathrm{ZnO}$ / PSM nanocomposites when the mass ratio of zinc acetate to PVA was separately chosen to be $3: 1,4: 1$ and $5: 1$ under the same annealing temperature of $800{ }^{\circ} \mathrm{C}$ for $30 \mathrm{~min}$. The highest PL intensity emission peak located at $397 \mathrm{~nm}$ can be obtained when the mass ratio is $4: 1$ for $\mathrm{ZnO} / \mathrm{PS}$ nanocomposites. The PL properties of $\mathrm{ZnO} / \mathrm{PS}$ nanocomposites are influenced by precursor solution of $\mathrm{ZnO}$.

It can be seen from those above experiments that the location of $\mathrm{ZnO}$ nanoparticles deposited on the oxidized PS is related to many factors, including 
surface structure of PS, precursor solution and post-annealing temperature of $\mathrm{ZnO}$. All those factors have a direct influence on the nanostructures and hence the optical properties of $\mathrm{ZnO} / \mathrm{PS}$ nanocomposites. In later experiments, we chose the mass ratio of zinc acetate to PVA to be $4: 1$, the annealing temperature to be $800{ }^{\circ} \mathrm{C}$ and the successive annealing time to be $30 \mathrm{~min}$, based on that the PL intensity of $\mathrm{ZnO} / \mathrm{PS}$ nanocomposites is the strongest under these conditions.

\section{3 $\mathrm{ZnO} / \mathrm{PSM}$ studies}

\subsubsection{Simulations and Fabrications}
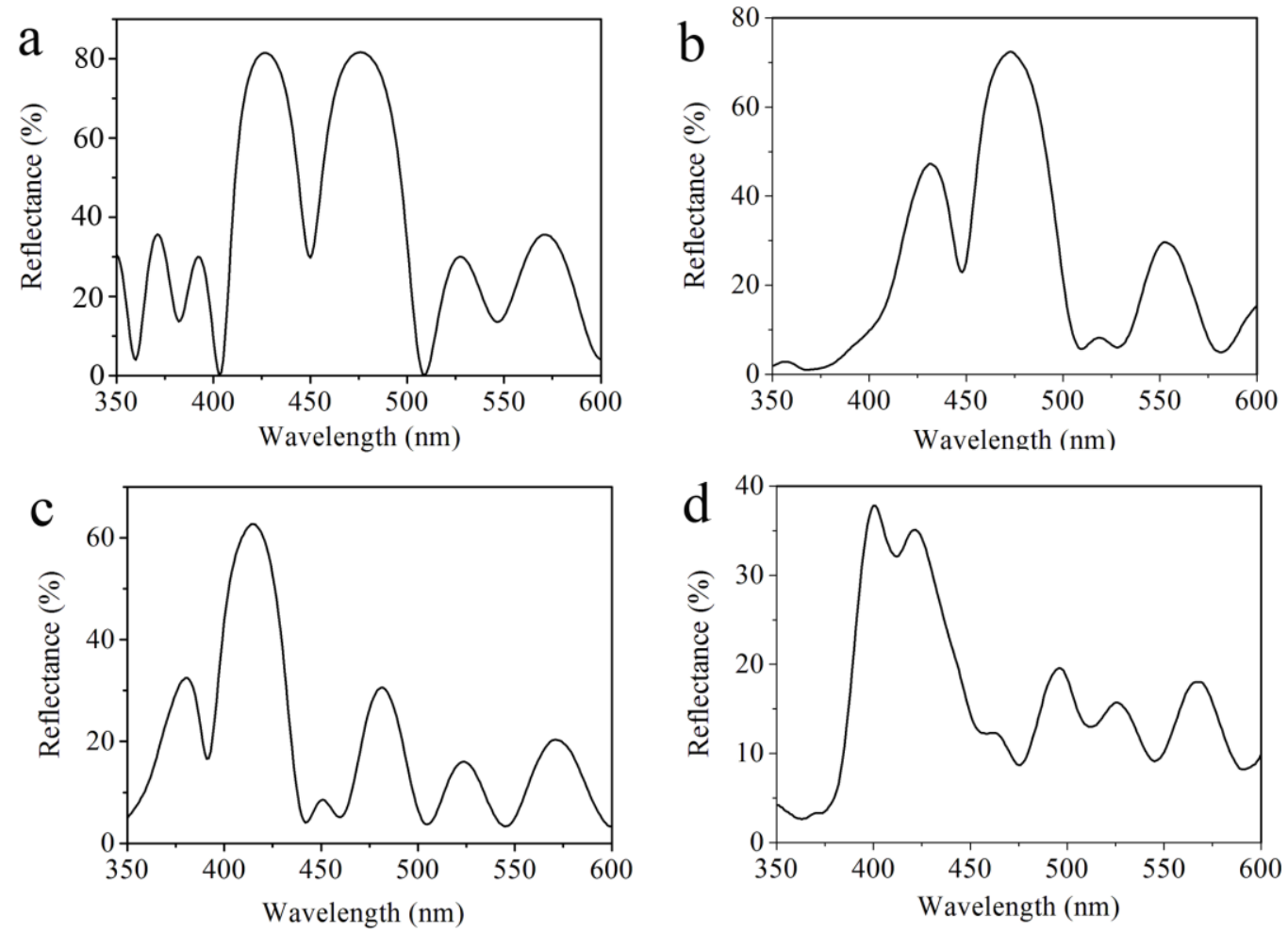

Fig.7. (a) Calculated reflectance spectrum of PSM following the $\left(n_{L} n_{H}\right)^{6} n_{L c}\left(n_{H} n_{L}\right)^{6}$ sequence. (b) Reflectance spectrum of fresh PSM with the same sequence. (c) Reflectance spectrum of oxidized PSM. (d) Reflectance spectrum of of ZnO/PS 
nanocomposite with a mass ratio of zinc acetate to PVA of $4: 1$ and the annealing temperature of $800{ }^{\circ} \mathrm{C}$.

In this section, whether the PL intensity of $\mathrm{ZnO} / \mathrm{PS}$ can be improved by PSM is studted. In order to determine proper optical parameters to obtain an ideal PSM in experiment, simulations of the reflectance spectrum had been performed. Considering that the resonance peak moves about $50 \mathrm{~nm}$ toward to short wavelength after oxidization in experiments, and the resonance peak for the fabricated $\mathrm{ZnO} / \mathrm{PS}$ was located at $400 \mathrm{~nm}$ in our case, we fabricated the PSM following $\left(\mathrm{n}_{\mathrm{L}} \mathrm{n}_{\mathrm{H}}\right)^{6} \mathrm{n}_{\mathrm{Lc}}\left(\mathrm{n}_{\mathrm{H}} \mathrm{n}_{\mathrm{L}}\right)^{6}$ sequence with a resonance peak to be $450 \mathrm{~nm}$.

Fig. 7(a) shows the reflectance spectrum for the calculated PSM following $\left(n_{L} n_{H}\right)^{6} n_{L c}\left(n_{H} n_{L}\right)^{6}$ sequence by using the transfer matrix method. The resolution of the grid in the digital simulation of reflectance spectrum was set to be $1 \mathrm{~nm}$. The reflective indexes were determined as $n_{L}=n_{L c}=1.33$ and $n_{H}=1.5$ by experiments, the layer thicknesses corresponding to those reflective indexes were $d_{H}=\lambda_{c} /\left(4 n_{H}\right)=85 \mathrm{~nm}$, $d_{L}=\lambda c /\left(4 n_{L}\right)=75 \mathrm{~nm}$, and the thickness of microcavity was $d_{L c}=\lambda_{\mathcal{C}} /\left(n_{L c}\right)=338 \mathrm{~nm}$ with $\lambda_{\mathrm{c}}$ denoting the resonance wavelength at $450 \mathrm{~nm}$. From Fig. 7(b), we can see a sharp resonant peak at $447 \mathrm{~nm}$ appeared in the experimentally measured reflectance spectrum for the freshly etched PSM, which is in good agreement to the calculated resonance peak of reflectance spectrum. The half maximum (FWHM) of resonance dip for the experimentally measured reflectance spectrum is about $11 \mathrm{~nm}$, and the reflectance spectrum shows all the important spectral features. 
Freshly etched PS is hydrogen terminated with $\mathrm{Si}-\mathrm{H}$ hydrideds on its surface which are very responsive, reactive and unstable, so PSM surface needs to be stabilized before immobilization. To do this, the fresh PSM was soaked in $\mathrm{H}_{2} \mathrm{O}_{2}(30 \%)$ for $24 \mathrm{~h}$ at room temperature. Due to the existence of $\mathrm{Si}-\mathrm{O}-\mathrm{Si}, \mathrm{O}-\mathrm{Si}-\mathrm{H}, \mathrm{O}_{3}-\mathrm{Si}-\mathrm{H}$ groups and bridging of inter-atomic silicon layers with $\mathrm{O}$ atoms, the PSM becomes stable. Furthermore, the refractive index of silicon-dioxide $\left(\mathrm{SiO}_{2}\right)$ is less than that of silicon and the decrease in the refractive index of PS layer of oxidized PSM results in a blue-shift of the reflectance spectrum. In Fig. 7(c), there is a blue-shift to $392 \mathrm{~nm}$ for the resonant peak of oxidized PSM, which is in good agreement to the PL emission of $\mathrm{ZnO}$ at around $400 \mathrm{~nm}$. In order to confirm $\mathrm{ZnO}$ nanoparticles to be well attached to PSM substrate, UV-vis spectrophotometer was used to measure the functionalization. In Fig. 7(d), the resulting resonant peak of reflectance spectra is red-shifted to $411 \mathrm{~nm}$. The red-shifted reflectance in our experiment suggests that the $\mathrm{ZnO}$ nanoparticles be coupled together well to PS layers. However, there are some differences between the reflectance spectra of PSM and ZnO/PSM in Fig. 7(c) and Fig. 7(d). We think these differences may come from that the $\mathrm{ZnO}$ nanoparticles had not penetrated uniformly enough into all layers of PSM, which will affects the refractive index of each layer in PSM.

\subsubsection{SEM images}



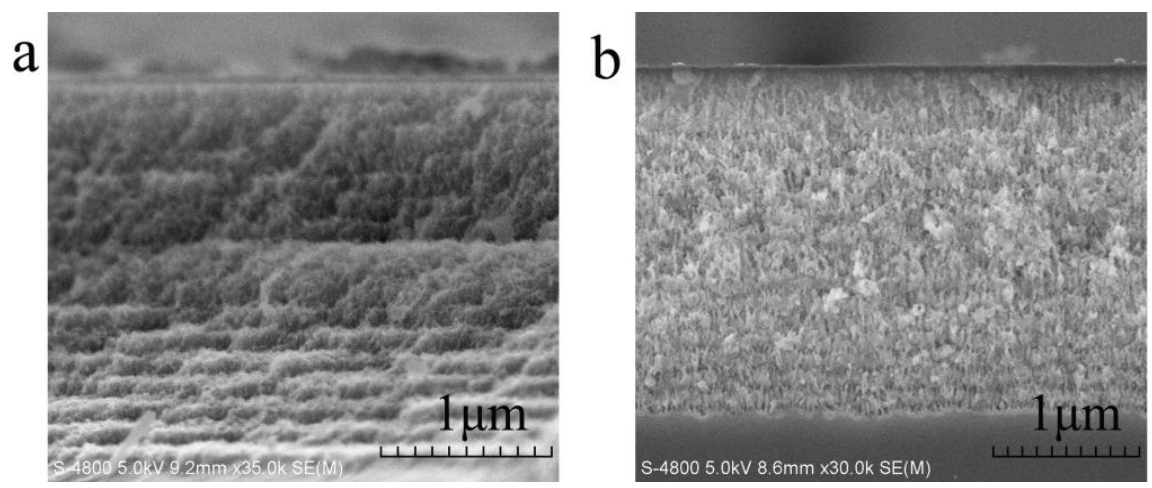

Fig. 8 Cross-sectional FESEM images of (a) oxidized PSM following $\left(n_{L} n_{H}\right)^{6} n_{L c}\left(n_{H} n_{L}\right)^{6}$ sequence, and (b) ZnO/PSM nanocomposite following the same sequence.

Fig. 8 shows cross-sectional FESEM images of the oxidized PSM and ZnO/PSM nanocomposite with the same sequence $\left(n_{L} n_{H}\right)^{6} n_{L c}\left(n_{H} n_{L}\right)^{6}$ and the same mass ratio of zinc acetate to PVA to be $4: 1$ at annealing temperature of $800^{\circ} \mathrm{C}$ with $30 \mathrm{~min}$. As shown in Fig. 8(a), there is a strong contrast between alternate layers of the oxidized PSM, which confirms that a large porosity difference has been achieved. The thickness of the PSM is about $2.3 \mu \mathrm{m}$. The dark gray layers are high porosity PS layers or low refractive index $\left(\mathrm{n}_{\mathrm{L}}\right)$ layers with thickness of $85 \mathrm{~nm}$, and the light gray layers are the low porosity PS layers or the high refractive index $\left(\mathrm{n}_{\mathrm{H}}\right)$ layers with a thickness of $75 \mathrm{~nm}$. The thickness of low refractive index $\left(\mathrm{n}_{\mathrm{Lc}}\right)$ microcavity layer is about $340 \mathrm{~nm}$. Fig. 8(b) shows the corresponding cross-section of ZnO/PSM, where $\mathrm{ZnO}$ nanoparticles penetrate uniformly into all PS layers and adhere to them very well.

\subsubsection{Photoluminescence studies}




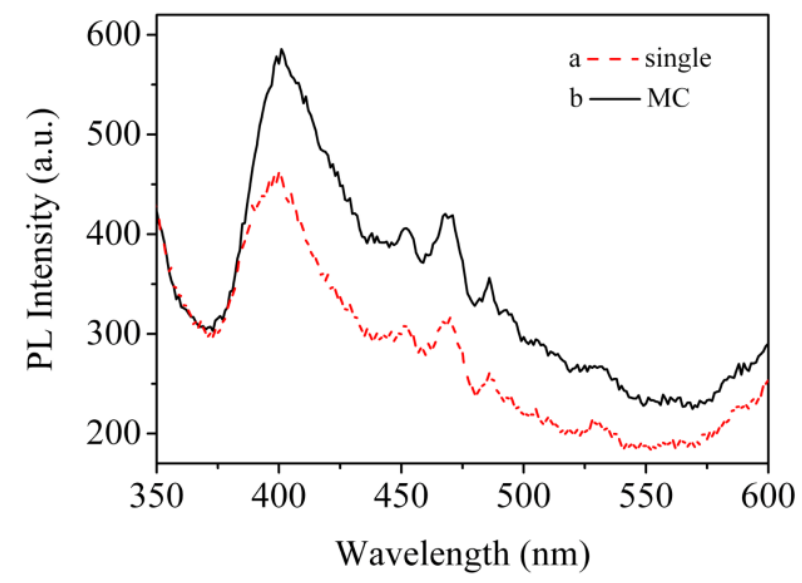

Fig. 9 Room-temperature PL spectra $(\lambda \mathrm{exc}=310 \mathrm{~nm})$ of (a) $\mathrm{ZnO} / \mathrm{PS}$ and (b) $\mathrm{ZnO} / \mathrm{PSM}$ nanocomposites following the sequence $\left(n_{L} n_{H}\right)^{6} n_{L c}\left(n_{H} n_{L}\right)^{6}$.

Fig. 9 shows the PL spectra of $\mathrm{ZnO} / \mathrm{PS}$ and $\mathrm{ZnO} / \mathrm{PSM}$ nanocomposites under the same conditions, i.e. the mass ratio of zinc acetate to PVA to be $4: 1$, annealing temperature to be $800{ }^{\circ} \mathrm{C}$ for $30 \mathrm{~min}$. Either $\mathrm{ZnO} / \mathrm{PS}$ or $\mathrm{ZnO} / \mathrm{PSM}$ exhibits a strong and broad band edge emission at approximately $400 \mathrm{~nm}$, which corresponds to the near band-edge emission of the wide band gap for $\mathrm{ZnO}$. An enhancement in the PL is observed from the cavity emission compared to the $\mathrm{ZnO}$ deposited directly onto the PS substrate, which means that one-dimensional photonic crystal PSM can enhance PL intensity of $\mathrm{ZnO} / \mathrm{PS}$ nanocomposites. The observed enhancement can be understood in terms of the spatial redistribution of the emitted light into a narrow cone normal to the surface. The presence of the cavity has significantly modified the spontaneous emission spectrum of spacer layer and affects the spontaneous emission rate and changes the rate of spontaneous emission (Purcell effect), hence to be planar semiconductor microcavity $[26,30]$. 


\section{Conclusions}

In this work, the PS and PSM were fabricated by electrochemical etching of P-type silicon. The high-density $\mathrm{ZnO}$ nanoparticles were grown onto PS and PSM substrates by sol-gel method. SEM images show the formation of $\mathrm{ZnO}$ nanoparticles on PS with a smooth surface and a uniform diameter. XRD spectrum confirms that such a $\mathrm{ZnO} / \mathrm{PS}$ nanocomposite exhibits high crystallinity and prefers strongly to (002) phase orientation. The PL spectra of $\mathrm{ZnO} / \mathrm{PS}$ nanocomposites show a sharp and strong UV emission peak located at $400 \mathrm{~nm}$. Furthermore, the PL spectra of $\mathrm{ZnO} / \mathrm{PSM}$ nanocomposites show relatively stronger UV emissions at $400 \mathrm{~nm}$ than that of $\mathrm{ZnO} / \mathrm{PS}$. The detailed cross-section image of $\mathrm{ZnO} / \mathrm{PSM}$ demonstrates that $\mathrm{ZnO}$ nanoparticles are penetrated uniformly into all PS layers and adhered to them very well. To the best of our knowledge, it is the first example of one-dimension photonic crystal PSM structure to enhance the PL intensity of ZnO/PS. Such an approach may suggest a way for the integration of future UV optoelectronic devices.

\section{Acknowledgments}

This work was supported by the National Science Foundation of China (No. 11504313, No.61665011), and Xinjiang Science and Technology Project (No.2015211C275). 


\section{References}

[1] Y. X. Wang, Z.Q. Hou, H. Guo, L. H. Shen, G. X. Wang, F. Cui, Q. Q. Zhang, Preparation of $\mathrm{ZnO}$ nanorods via aqueous solution process and their PL properties, Materials Letters, 91(15), 107-110, 2013.

[2] N. R. Panda, B. S. Acharya, P. Nayak, B. P. Bag, Studies on growth morphology $\mathrm{UV}$ absorbance and luminescence properties of sulphur doped $\mathrm{ZnO}$ nanopowders synthesized by the application of ultrasound with varying input power, Ultrasonics Sonochemistry, 21, 582-589, 2014.

[3] A. E. Rakhshani, Visible light emission and UV light detection properties of solution-grown $\mathrm{ZnO}$ /polymer hetero junction diodes on stainless steel foil, Applied Surface Science, 311, 614-620, 2014.

[4] F. P. Peng, Q. Zhou, D. P. Zhang, C. H. Lu, Y. Ni, J. H. Kou, J. Wang, Z. Z. Xu, Bio-inspired design: Inner-motile multifunctional $\mathrm{ZnO} / \mathrm{CdS}$ heterostructures magnetically actuated artificial cilia film for photocatalytic hydrogen evolution, Applied Catalysis B: Environmental, 165, 419-427, 2015.

[5] T. Park, E. Park, J. Ahn, J. Lee, J. Lee, S. Lee, et al. Optical Properties and Field Emission of ZnO Nanorods Grown on p-Type Porous Si, Bull Korean Chem Soc, 34(6), 1779-1782, 2013.

[6] M.S. Kim, K.G. Yim , D.Y. Kim , S. Kim, G. Nam , D.Y. Lee , et al, Growth and characterization of seed layer-free $\mathrm{ZnO}$ thin films deposited on porous silicon by 
hydrothermal method, Electronic Materials Letters. 8(1), 75-80, 2012.

[7] M. Rajabi, R. Dariani, Growth of $\mathrm{ZnO}$ Nanostructures on Porous Silicon and Oxidized Porous Silicon Substrates, Brazilian Journal of Physics, 41(2),113-117, 2011.

[8] S.Q. Chen, J. Zhang, X. Feng, X.H. Wang, L.Q. Luo, Y.L. Shi, et al. Nanocrystalline $\mathrm{ZnO}$ thin films on porous silicon/silicon substrates obtained by sol-gel technique, Applied Surface Science, 241(3-4), 384-391, 2005.

[9] R. Ghosh, P. K. Giri, K. Imakita, M. Fujii, Photoluminescence signature of resonant energy transfer in $\mathrm{ZnO}$ coated $\mathrm{Si}$ nanocrystals decorated on vertical $\mathrm{Si}$ nanowires array, Journal of Alloys and Compounds, 638, 419-428, 2015.

[10] E. Makarona , M. C. Skoulikidou, T. Kyrasta, A. Smyrnakis, A. Zeniou, E. Gogolides, C. Tsamis, Controllable fabrication of bioinspired three-dimensional ZnO/Si nanoarchitectures, Materials Letters, 142, 211-216, 2015.

[11] S. Chu, M. Olmedo, Z. Yang, J. Y. Kong, J. L. Liu, Appl. Phys. Lett., 93, 181106, 2008.

[12] H.Y. Zhang, X.Y. Lv, C.W. Lv, Z.H. Jia, n-Type porous silicon as an efficient surface enhancement Raman scattering substrate. Optical Engineering, 51(9), 099003(1-5), 2012.

[13] H. Y. Zhang, Z. H. Jia, X. Y. Lv, J. W. Hou, X. J. Liu, J. Ma, J. Zhou, Antifreeze protein detection using Rhodamine B as photoluminescence label in porous silicon. 
Current Applied Physics, 13(4), 736-742, 2013.

[14] D. Verma, A. Kharkwal, S. N. Singh, P. K. Singh, S. N. Sharma, S. S. Mehdi, Application of $\mathrm{ZnO}$ nanostructures to enhance photoluminescence in porous silicon and its possible utilization for improving the short wavelength quantum efficiency of silicon solar cell, Solid State Sciences, 37, 13-17, 2014.

[15] S. Y. Ma, X. H. Yang, X. L. Huang, A. M. Sun, H. S. Song, H. B. Zhu, Effect of post-annealing treatment on the microstructure and optical properties of $\mathrm{ZnO} / \mathrm{PS}$ nanocomposite films, Journal of Alloys and Compounds, 566(25), 9-15, 2013.

[16] H. S. Al-Salman, M. J. Abdullah, Preparation of $\mathrm{ZnO}$ nanostructures by RF-magnetron sputtering on thermally oxidized porous silicon substrate for VOC sensing application, Measurement, 59, 248-257, 2015.

[17] K. A. Eswar, J. Rouhi, F. S. Husairi, R. Dalvand, S. A. H. Alrokayan, H. A. Khan, M. Rusop Mahmood, S. Abdullah, Hydrothermal growth of flower-like $\mathrm{ZnO}$ nanostructures on porous silicon substrate, Journal of Molecular Structure, 1074, 140-143, 2014.

[18] F. S. Husairi, A. Azlinda, M. Rusop, S. Abdullah, Photoluminescence properties of Zinc Oxide nanostructures on different substrates obtained by an immersion method, Microelectronic Engineering, 108, 145-149, 2013.

[19] L. J. Adam, G. S. Adrian, S. Adnan, M. J. Sailor, G. M. Miskelly, Real-time 1D hyperspectral imaging of porous silicon-based photonic crystals with one-dimensional 
chemical composition gradients undergoing pore-filling-induced spectral shifts, Sensors and Actuators A, 203, 154-159, 2013.

[20] H. Y. Zhang, Z. H. Jia, X. Y. Lv, J. Zhou, L. L. Chen, R. X. Liu, J. Ma, Porous silicon optical microcavity biosensor on silicon-on-insulator wafer for sensitive DNA detection, Biosensors and Bioelectronics, 44(15), 89-94, 2013.

[21] I. Sua'rez, V. Chirvony, D. Hill, J. Mart1'nez-Pastor, Simulation of surface-modified porous silicon photonic crystals for biosensing applications, Photonics and Nanostructures - Fundamentals and Applications, 10(3), 304-311, 2012.

[22] S. Y. Um, J. Yang, T. E. Choi, H. Y. Cho, S. Jin, H. Sohn, Fabrication and optical characterization of full color stop band based on rugate-structured porous silicon, Microelectronic Engineering, 89, 100-103, 2012.

[23] N. H. Maniya, S. R. Patel, Z. V. P. Murthy, Simulation and fabrication study of porous silicon photonic crystal, Optik 125(2), 828-831, 2014.

[24] A. S. Kuchyanov, P. A. Chubakov, A. I. Plekhanov, Highly sensitive and fast response gas sensor based on a light reflection at the glass-photonic crystal interface, Optics Communications, 351, 109-114, 2015.

[25] M. Turduev, I. H. Giden, H. Kurt, Design of flat lens-like graded index medium by photonic crystals: Exploring both low and high frequency regimes, Optics Communications, 339, 22-33, 2015. 
[26] H. Qiao, B.Guan, T. Böcking, M. Gal, J. J. Gooding, P. J. Reece, Optical properties of II-VIcolloidal quantum dot doped porous silicon microcavities, Applied physics letters, 96(16), 161106, 2010.

[27] H. I. Abdulgafour, F. K. Yam, Z. Hassan, K. AL-Heussen, M. J. Jawad, ZnO nanocoral reef grown on porous silicon substrates without catalyst, Journal of Alloys and Compounds, 509(18), 5627-5630, 2011.

[28] Z. M. Liao, J. Xu, J. M. Zhang, D. P. Yu, photovoltaic effect and charge storage in single $\mathrm{ZnO}$ nanowires, Applied physics letters, 93(2), 23111 (1-3), 2008.

[29] M. Rajabi , R.S. Dariani , A.I. Zad , Comparative study of ZnO nanostructures grown on silicon (100) and oxidized porous silicon substrates with and without $\mathrm{Au}$ catalyst by chemical vapor transport and condensation, Journal of Alloys and Compounds, 509(11), 4295-4299, 2011.

[30] P. J. Reece, G. Lerondel, W. H. Zheng, M. Gal, Optical microcavities with subnanometer line widths based on porous silicon, Applied physics letters, 81(26), 4895-4897, 2002. 